Artigo de Pesquisa

\title{
Qualidade Decisória dos Gestores Públicos: Contribuições da Inteligência e Gestão do Conhecimento
}

\section{Decision-Making Quality of Public Managers: Contributions from Intelligence and Knowledge Management}

\author{
Claudia Melati \\ Raquel Janissek-Muniz ${ }^{1 \oplus}$ \\ Carla Maria Marques Curado ${ }^{2}$
}

\section{RESUMO}

Contexto: nos últimos anos, estudos buscaram analisar de que forma os processos de inteligência e de gestão do conhecimento são compreendidos e aplicados no contexto da gestáo pública, ambiente em que esses processos aparecem como um ponto a ser explorado para potencializar a qualidade decisória. Objetivo: analisar como os gestores públicos aplicam inteligência e gestáo do conhecimento visando a uma maior qualidade decisória. Método: a partir de protocolo de pesquisa definido e validado, foram realizadas entrevistas com dezessete gestores públicos do sul do Brasil. Para a análise, foi aplicada a técnica de análise comparativa qualitativa utilizando conjuntos fuzzy para identificar caminhos efetivos para tomada de decisão em Governo. Resultados: os resultados indicam a importância da efetiva gestão de dados, informaçôes e conhecimentos para qualidade decisória de gestores públicos, demonstrando que a pouca qualidade decisória está relacionada à ausência ou à reduzida utilização de gestão do conhecimento e inteligência na gestão pública. Conclusáo: além de analisar condiçôes e propor caminhos para levar a uma maior qualidade na tomada de decisão dos gestores públicos, foi possível contribuir para a temática de gestáo do conhecimento e inteligência na gestáo pública, bem como beneficiar o governo com caminhos a serem consolidados e melhor explorados.

Palavras-chave: gestão pública; gestão do conhecimento; inteligência; análise comparativa qualitativa; conjuntos fuzzy.

1. Universidade Federal de Rio Grande do Sul, Escola de Administração, Porto Alegre, RS, Brasil.

2. Universidade de Lisboa, Instituto Superior de Economia e Gestão, Lisboa, Portugal.

Como citar: Melati, C., Janissek-Muniz, R., \& Curado, C. M. M. (2021). Qualidade decisória dos gestores públicos: Contribuições da inteligência e gestão do conhecimento. Revista de Administração Contemporânea, 25(2), e190044. https://doi.org/10.1590/1982-7849rac2021190044.por

\section{ABSTRACT}

Context: in recent years, studies have sought to analyze how intelligence and knowledge management processes are understood and applied in the context of public management, environments in which processes appear as a point to be explored to enhance decision-making quality. Objective: to analyze how public managers apply intelligence and knowledge management aiming at a higher decision quality. Method: based on a defined and validated research protocol, interviews were conducted with seventeen public managers in southern Brazil. For the analysis, the qualitative comparative analysis technique using fuzzy sets was applied. Results: the results suggest the importance of effective data, information, and knowledge management for the decision-making quality of public managers, demonstrating that the absence of decision-making quality is directly related to the absence or little use of knowledge management and intelligence elements in the public management. Conclusion: in addition to analyzing conditions and proposing ways to lead to greater quality in decision making by public managers, it was possible to contribute to the theme of knowledge management and intelligence in public management, as well as to benefit the government with paths to be consolidated and better explored.

Keywords: public management; knowledge management; intelligence; qualitative comparative analysis; fuzzy sets.

Classificação JEL: D7, D8, H1

Editor-chefe: Wesley Mendes-Da-Silva (Fundação Getulio Vargas, EAESP, Brasil) (1) areceristas: Amanda Cainelli (Universidade Federal do Rio Grande do Sul, EA, Brasil) Natália Marroni Borges (Universidade Federal do Rio Grande do Sul, EA, Brasil) Relatório de Revisão por Pares: O Relatório de Revisão por Pares está disponivel neste link externo.

Recebido: $23 / 04 / 2019$ recebida em: 25/06/2020 Aceite em: 25/06/2020

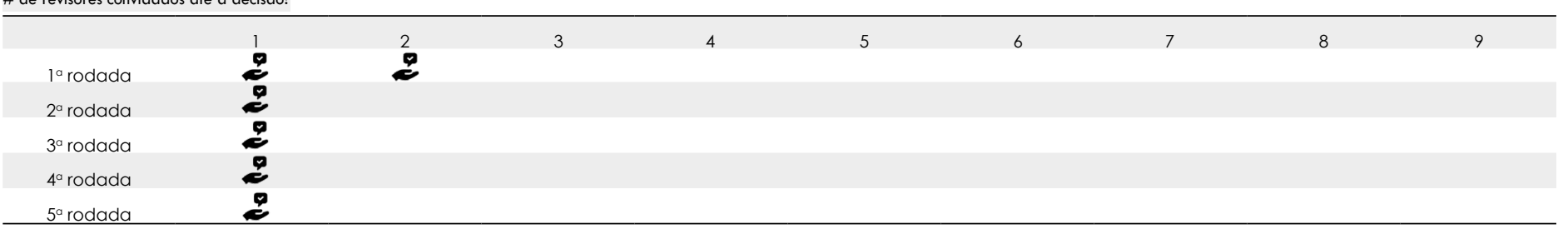




\section{INTRODUÇÃO}

A partir do uso intensivo de TICs (tecnologias da informação e comunicação) na Gestão Pública, houve um aumento considerável de dados e informaçóes advindos da sociedade, demandados por ela ou produzidos nas organizaçóes públicas. Este contexto demandou da Gestáo Pública uma preocupação maior em relação à gestão da informação e do conhecimento produzido e utilizado. Segundo pesquisa da Forrester Research (Welsh, 2014), publicada na revista Information Week Government, as agências governamentais devem estar atentas e buscar encontrar maneiras mais efetivas de aproveitar dados, visando a atender as expectativas dos cidadãos e a realizar prestação de serviços, considerando o exponencial volume de dados, sem precedentes, e a conectividade móvel generalizada (Scholl \& Scholl, 2014; Gil-Garcia, Zhang, \& Puron-Cid, 2016).

Pesquisas apontam que os governos, em diferentes níveis e ramos, estão adotando ferramentas e aplicaçóes para uma melhor entrega de serviços à sociedade, visando a se organizarem para responder com agilidade às rápidas transformações do ambiente (Gil-Garcia, Helbig, \& Ojo, 2014; Paula \& Rover, 2012; Ribeiro, Pereira, \& Benedicto, 2013). Dentre essas ferramentas de gestão, está a atividade de Inteligência em governo, que apesar de ainda estar em estágios iniciais de desenvolvimento, contribui para um novo modelo de prestação de serviços públicos (Schedler, Guenduez, \& Frischknecht, 2019).

Ao aproveitar os dados e informaçóes para qualificar a tomada de decisão do gestor público e para o desenvolvimento eficiente de novas políticas públicas, a estruturação da atividade de Inteligência contribui para novos resultados no setor público. Nesta linha, Cavalcante (2018) sugere que as transformaçôes econômicas, sociais e político-administrativas das últimas décadas têm efetivamente potencializado uma variedade de processos de reestruturação, alavancando melhores entregas à sociedade $\mathrm{e}$ trazendo importantes resultados no setor público brasileiro.

O desenvolvimento da Administração Pública com entrega ágil de serviços aos cidadáos, com eficiência na prestação do serviço e na resolução de questôes de governo e sociedade, com colaboração interdepartamental, bem como a implantação de uma mistura criativa de tecnologias emergentes para inovação no setor público (Eom, Choi, \& Sung, 2016; Liu \& Zheng, 2015), aparece como objetivos na nova maneira de pensar a Gestão Pública. Novos processos de gestão, assim como o de Gestão do Conhecimento (GC) e o de Inteligência, demonstram-se eficazes para explorar dados e informaçóes do ambiente externo, visando à transformação destes em conhecimento relevante para maior Qualidade na Tomada de Decisão do Gestor Público (Gil-Garcia et al., 2016; Johnston \& Hansen, 2011; Monavvarian \& Kasaei, 2007; Shinoda, Maximiano, \& Sbragia, 2015).

Com o auxílio de atividades associadas aos processos de Inteligência, as organizaçóes são capazes de selecionar de forma pertinente a quantidade de dados gerados pelo ambiente externo, a partir das atividades de monitoramento, observação, coleta, interpretação, criação de sentido e divulgação, alimentando a tomada de decisão mais assertiva, fundamentada em informaçóes sensíveis, úteis e baseadas em sinais (Gil-Garcia et al., 2016; JanissekMuniz \& Blanck, 2014; Scholl \& Scholl, 2014). Por sua vez, a Gestão do Conhecimento se refere a uma série de práticas e técnicas utilizadas pelas organizaçóes para criar, compartilhar e explorar o conhecimento para atingir as metas organizacionais (Davenport, 1997; Nonaka \& Takeuchi, 2008; Arora, 2011; Jain \& Jeppesen, 2013).

A Gestão do Conhecimento melhora a capacidade de realizaçáo das atividades públicas, com práticas que podem aumentar a efetividade dos serviços públicos e melhor atender a sociedade a qual serve, contribuindo com a comunicação entre os níveis de gestão (Wiig, 2002; Monavvarian \& Kasaei, 2007). Os referidos estudos demonstram a importância do aproveitamento de processos de Gestão do Conhecimento e Inteligência para a maior Qualidade na Tomada de Decisão do Gestor Público (Alavi \& Leidner, 2001; Desouza, 2005; Hazlett, McAdam, \& Beggs, 2008; Johnston \& Hansen, 2011; Linders, Liao, \& Wang, 2015; Shinoda et al., 2015). Enquanto as atividades de Inteligência estratégica priorizam o olhar para o ambiente externo e a relação deste com a organização, a gestão de conhecimento tem uma perspectiva mais interna e voltada aos conhecimentos já existentes na organização (Benedetti \& Janissek-Muniz, 2009).

Apesar da existência de estudos já desenvolvidos em Inteligência e GC na Gestão Pública, a partir da revisão da literatura existente, verificou-se que a associação de ambos os processos (Inteligência e GC) no contexto da Gestão Pública apresenta-se como uma lacuna a ser investigada. Tal questão é reforçada pelo Modelo de Excelência da Gestão Pública - MEGP (Ministério do Planejamento, 2016), que sugere que, a partir do pilar de informação e conhecimento, são avaliados e processados os dados e fatos (internos) da organização, bem como aqueles provenientes do ambiente (externo) que não estão sob o controle direto, mas que podem influenciar no seu desempenho. Ainda, segundo Terra e Almeida (2008), o estudo dos conceitos de GC e Inteligência, bem como o desenvolvimento de atividades relacionadas aos processos, deveria ser tratado de maneira conjunta e alinhado à estratégia organizacional, buscando sinergias e alocação ótima de recursos e tempos. 
Adicionalmente, estudos apontam que há poucos esforços relatados (1) na alavancagem do uso de dados sociais para a opinião inteligente em governo; (2) na efetiva utilização de dados e informaçóes advindos dos cidadãos; (3) nas interaçóes dinâmicas entre as partes interessadas; e (4) na influência e desenvolvimento de políticas públicas (Bernardes, Andrade, Novais, \& Lopes, 2017; McBride, Aavik, Lalvet, \& Krimmer, 2018; Przeybilovicz, Cunha, Macaya, \& Alburquerque, 2018). Neste sentido, a questão que suporta esta pesquisa é: com base nos elementos dos processos de Gestão do Conhecimento e de Inteligência, quais caminhos podem ser efetivos para a maior Qualidade na Tomada de Decisão do Gestor Público?

Assim, o objetivo da pesquisa consiste em identificar caminhos que se demonstrem efetivos para a maior Qualidade na Tomada de Decisão do Gestor Público a partir da utilização de elementos dos processos de Gestão do Conhecimento e de Inteligência. Para tal, primeiramente foram analisadas questôes relativas à Gestão do Conhecimento e Inteligência na Gestão Pública, seguindo com a realização de entrevistas com dezessete gestores públicos que foram analisadas através da técnica de análise de conteúdo e, posteriormente, para definição de caminhos, aplicou-se a análise comparativa qualitativa.

Como contribuição desta pesquisa, pretende-se alavancar o entendimento da Gestáo do Conhecimento e a Inteligência na Gestáo Pública, entendendo que tal aproximação pode ser útil em um contexto em que os governos estâo diante de uma quantidade sem precedentes de dados e informaçóes, os quais precisam ser monitorados, explorados, compreendidos, transformados em conhecimentos, e convertidos em açóes para a qualificação da tomada de decisão dos gestores públicos. Ainda, no que tange à aplicabilidade do estudo, entende-se que, ao apresentar a importância de processos de Gestáo do Conhecimento e Inteligência na Gestáo Pública, a partir de caminhos a serem consolidados e melhor explorados pelo governo, possa haver um potencial aproveitamento de dados e informaçóes do ambiente para a decisão governamental.

Para tratar desta problemática, este artigo está organizado de forma a, após introduzir a temática, apresentar os conceitos de Gestáo do Conhecimento e Inteligência no contexto da Gestão Pública e possíveis aproximaçóes. $\mathrm{Na}$ sequência, a seção metodológica estabelece as escolhas das abordagens utilizadas na presente pesquisa, tratando especificamente da análise comparativa qualitativa. A seção posterior traz a apresentação dos resultados da aplicação metodológica. Finalmente, as discussóes, conclusōes e direcionamentos do estudo são apresentados.

\section{GESTÃO DO CONHECIMENTO E INTELIGÊNCIA NO CONTEXTO PÚBLICO}

A partir dos anos 90, o governo brasileiro iniciou um processo de modernização da Administração Pública, com foco central na eficiência mediante a busca de reduçáo de custos e na obtençáo de resultados no desenvolvimento da atividade pública no Brasil, visando a pressupostos mais gerenciais e menos burocráticos (Abrucio, 1997; Batista, 2012; Klering, Porsse, \& Ghadagnin, 2010; Paula, 2005; Pereira, 1996). Conforme Ribeiro, Pereira e Benedicto (2013), as reformas da Administração Pública têm contribuído para melhorar a capacidade de decisão política e para a descentralização do Estado, com a implementação da coordenação horizontal e modernização do potencial humano de gestão. A tendência está na construção de uma Administração Pública mais participativa, eficiente e integrada em rede (Capobiango, Nascimento, Silva, \& Faroni, 2013; Paula, 2005; Secchi, 2009), propiciando uma melhor Gestão Pública na entrega de serviços à sociedade.

Rezende e Frey (2005), reconhecendo as novas potencialidades relacionadas à ampliação dos atores envolvidos na Gestáo Pública, salientam que tais direcionamentos da Administração Pública e da gestão de políticas públicas necessitam da mobilização de todo o conhecimento disponível na sociedade, em benefício da melhoria do desempenho administrativo e da democratização dos processos decisórios. Estudos também apontam a importância da aquisiçáo de dados a serem transformados em informaçóes e conhecimento para o aprimoramento da tomada de decisão no setor público (Gil-Garcia, Pardo, \& Aldama-Nalda, 2013; Scholl \& Scholl, 2014), uma vez que governos inteligentes podem ser potencialmente capazes de sentir e reagir ao ambiente com base em dados relevantes para a tomada de decisão (Gil-Garcia et al., 2016).

Na mesma linha, o Programa Nacional de Gestão Pública e Desburocratização - conhecido como Gespública - busca, desde os anos 2000, apoiar o desenvolvimento e a implantação de soluções que permitam um contínuo aperfeiçoamento de gestáo das organizaçóes públicas e seus impactos junto aos cidadãos. A informação e o conhecimento sáo apresentados como um dos pilares fundamentais para atingir um dos principais objetivos, que é a mobilização da Administração Pública brasileira na direção da geração de resultados (Ministério do Planejamento, 2016).

O processo de Inteligência na Gestão Pública é citado como pertinente aos objetivos de modernização administrativa, e envolve questóes peculiares quando comparadas ao setor privado. Diversos autores ressaltam a importância da realização contínua de processos de monitoramento do ambiente e análise de dados e informaçóes em governo (Cepik, 1997, 2005; Desouza, 
2005; Johnston \& Hansen, 2011; Linders et al., 2015). Questôes relacionadas à eficiência da atividade pública e à entrega de serviços públicos de qualidade para a sociedade, a partir do uso de informaçóes advindas do ambiente, caracterizam a utilização de atividades de Inteligência em Gestão Pública (Gil-Garcia et al., 2014; Scholl \& Scholl, 2014).

Segundo Rezende (2012), Inteligência na Administração Pública está relacionada com o uso de informaçóes e conhecimentos sistematizados, personalizados e oportunos para a tomada de decisáo, visando a auxiliar o gestor público a lidar com a complexidade e incertezas por meio da coordenação, envolvimento continuado, acesso a dados abertos e informaçóes compartilhadas (Gil-Garcia et al., 2014; Scholl \& Scholl, 2014), dentro do objetivo de aproveitar as habilidades e conhecimentos potencialmente latentes na multidão (Johnston \& Hansen, 2011).

Mapeadas a partir da literatura sobre a temática, podemos citar algumas dimensóes importantes do processo de Inteligência na Gestão Pública, a saber: o Apoio da Alta Gestão por meio do incentivo ao monitoramento do ambiente com o objetivo de captar dados e informaçóes pertinentes para a construção de uma Administração Pública mais eficiente (Gil-Garcia et al., 2016); a colaboração e a participação das pessoas como receptoras de dados e informações advindos do monitoramento do ambiente e pertinentes para organização (Gil-Garcia et al., 2016; Johnston \& Hansen, 2011; Paula \& Rover, 2012); o uso da tecnologia da informação e comunicação para a coleta de dados do ambiente externo, bem como para o auxílio no compartilhamento dos dados e informaçóes entre as partes interessadas (Paula \& Rover, 2012; Scholl \& Scholl, 2014).

Contudo, apenas obter informação do ambiente através de processos de Inteligência não é suficiente. Todo o conhecimento gerado a partir de dados e informaçóes advindos do ambiente externo, bem como aquele produzido na organização, precisa ser gerenciado (Tzortaki \& Mihiotis, 2014). Desta forma, o processo de Gestáo do Conhecimento se estabelece a partir da capacidade da organização em reunir, armazenar e transferir conhecimento, propiciando o acesso a fontes de conhecimento por meio de mecanismos de identificação e recuperação de informaçóes, com o objetivo de aplicar o conhecimento às necessidades específicas da organização (Alavi \& Leidner, 2001).

Segundo Riege e Lindsay (2006), para construção de um governo mais eficaz e para o desenvolvimento de políticas públicas calcadas em conhecimento, a Gestão Pública deve atentar para uma forma mais sistemática e eficaz de captura, difusão, transparência e aplicação do conhecimento organizacional. Deve, ainda, utilizar práticas e técnicas para criar, compartilhar e explorar o conhecimento a fim de auxiliar no atingimento de metas organizacionais
(Jain \& Jeppesen, 2013). Neste sentido, há um esforço das agências governamentais em adotar práticas de Gestão do Conhecimento com a missão de criar sistemas inovadores e complexos que conectem as pessoas com informaçóes e conhecimentos pertinentes para o desenvolvimento de suas atividades (Riege \& Lindsay, 2006), uma vez que o conhecimento das pessoas é caracterizado como sendo de valor central de uma organização (Voronchuk \& Starineca, 2014).

Como dimensões importantes da Gestão do Conhecimento na Gestão Pública, a partir da análise da temática na área, destacam-se: o Apoio da Alta Gestão para criação, disseminação e armazenamento do conhecimento organizacional, objetivando o desenvolvimento de políticas organizacionais orientadas à aprendizagem e GC (Hazlett et al., 2008; Lindner \& Wald, 2011; Shinoda et al., 2015); e o uso de tecnologias da informação e comunicação como meio facilitador no desenvolvimento do processo de GC, uma vez que por meio de sua utilização é possível, de forma mais rápida, obter, compartilhar e armazenar o conhecimento (Arora, 2011; Dawes, Cresswell, \& Pardo, 2009; Mao, Liu, Zhang, \& Deng, 2016; Schutte \& Barkhuizen, 2015). Ainda, o capital humano aparece como protagonista do processo de GC, uma vez que são as pessoas que exercem o poder da decisão com auxílio da utilização do conhecimento que é criado, obtido, disseminado e armazenado na organizaçáo (Arora, 2011; Davenport, 1998; Monavvarian \& Kasaei, 2007; Voronchuk \& Starineca, 2014; Wiig, 2002).

Diante da análise dos conceitos de Inteligência e Gestão do Conhecimento em governo, são estabelecidos alguns fatores fundamentais que permeiam ambos os processos, como, por exemplo, o uso de tecnologias da informação e da comunicação e o papel das pessoas como agentes primordiais do processo de Inteligência e de Gestão do Conhecimento. Adicionalmente, o Apoio da Alta Gestáo $\mathrm{e}$ as questóes da cultura e de incentivo organizacional aparecem como fatores importantes na construção de uma organização pública mais eficiente no processo de captação, transformaçáo e gerenciamento de informaçáo e conhecimento.

A partir da aproximação dos conceitos, consideramse, em ambos os processos (Inteligência e Gestão do Conhecimento) no setor público, as tecnologias da informação e comunicação, o capital humano (pessoas) e o Apoio da Alta Gestão como fatores determinantes no processo. Além disso, a eficiência e a eficácia do governo, bem como a melhor tomada de decisão dos gestores, aparecem como consequentes da utilizaçáo efetiva de mecanismos de Inteligência e Gestáo do Conhecimento no desenvolvimento da atividade pública. Assim, o processo de Inteligência se estabelece a partir do monitoramento do ambiente externo para fins de captaçáo de dados e informaçóes pertinentes 
à organizaçáo (Janissek-Muniz, Lesca, \& Freitas, 2006), enquanto a GC busca a transformaçáo dos dados e informações advindos do ambiente em conhecimento, visando a criar, compartilhar e explorar o conhecimento para a tomada de decisão (Gil-Garcia et al., 2013; Johnston \& Hansen, 2011; Wiig, 2002).

Assim, com o objetivo de retomar os principais pontos elencados na análise teórica, a Tabela 1 apresenta perspectivas, autores e pressupostos básicos relacionados aos processos de Gestão do Conhecimento e Inteligência com foco no contexto da Gestáo Pública.

Considerando os estudos desta revisão, evidenciase, portanto, a importância dos processos de Gestão do Conhecimento e Inteligência para a Gestão Pública e a necessidade de continuidade de pesquisas na referida área. Desta forma, a partir dos procedimentos metodológicos aplicados no presente estudo, buscou-se a consolidação da importância destes processos para a maior Qualidade na Tomada de Decisão do Gestor Público.

Tabela 1. Perspectivas teóricas.

\begin{tabular}{|c|c|c|}
\hline Categorias & Pressupostos teóricos & Autores \\
\hline Gestão do Conhecimento & $\begin{array}{l}\text { A Gestão do Conhecimento visa, através da criação, armazenamento, } \\
\text { disseminaçáo, proteçáo, partilha e uso do conhecimento, a } \\
\text { maximizar a eficiência da empresa. O conhecimento é um ativo das } \\
\text { organizaçóes que deve passar por uma eficiente gestão e ser renovado } \\
\text { constantemente para gerar retorno e vantagem competitiva. }\end{array}$ & $\begin{array}{l}\text { Alavi e Leidner (2001); Davenport (1997); Gaspar, } \\
\text { Santos, Donaire, Kuniyoshi e Prearo (2016); Gold, } \\
\text { Malhotra e Segars (2001); Nonaka (1994); Nonaka e } \\
\text { Konno (1998); Nonaka e Takeuchi (2008); Wiig (1997, } \\
\text { 2002). }\end{array}$ \\
\hline Inteligência & $\begin{array}{l}\text { Habilidade das organizaçóes em coletar, analisar e disseminar dados } \\
\text { e informaçóes (pertinentes ao desenvolvimento de suas atividades) } \\
\text { advindos do ambiente externo, tendo por base os objetivos e } \\
\text { estratégias organizacionais, além de contribuir na redução de } \\
\text { incertezas na tomada de decisão. }\end{array}$ & $\begin{array}{l}\text { Andriotti, Freitas e Janissek-Muniz (2008); Davenport } \\
\text { (1998); Fachinelli, Glacomello, Rech e Bertolini (2013); } \\
\text { Janissek-Muniz et al. (2006); Janissek-Muniz e Blanck } \\
\text { (2014); Rios, Strauss, Janissek-Muniz e Brodbeck } \\
\text { (2011). }\end{array}$ \\
\hline $\begin{array}{l}\text { Convergência entre } \\
\text { Gestáo do Conhecimento } \\
\text { e Inteligência na Gestão } \\
\text { Pública }\end{array}$ & $\begin{array}{l}\text { Apoio da alta gestão como incentivo organizacional para a criação, } \\
\text { o compartilhamento e o armazenamento do conhecimento } \\
\text { organizacional. Criação de uma cultura organizacional voltada } \\
\text { para o monitoramento do ambiente com o objetivo de captação } \\
\text { de dados e informaçóes. Uso de tecnologia da informação e } \\
\text { comunicaçáo (TIC) favorece o compartilhamento de informaçóes } \\
\text { e conhecimento entre as partes interessadas, sendo a tecnologia o } \\
\text { meio facilitador na captação de dados e informações do ambiente. } \\
\text { Capital humano como protagonista da GC. São as pessoas que } \\
\text { exercem o poder da decisão através do uso do conhecimento criado, } \\
\text { obtido, disseminado e armazenado na organização. Importância } \\
\text { de aproveitar habilidades e conhecimentos muitas vezes latentes } \\
\text { na multidão, e buscar a colaboração e participação das pessoas na } \\
\text { busca pela eficiência e eficácia da atividade pública. Pessoas como as } \\
\text { receptoras de dados e informaçóes advindos do ambiente. }\end{array}$ & $\begin{array}{l}\text { Dawes, Cresswell e Pardo (2009); Gil-Garcia et al. } \\
\text { (2013); Gil-Garcia et al. (2016); Hazlett, Mcadam } \\
\text { e Beggs (2008); Johnston e Hansen (2011); Lindner } \\
\text { e Wald (2011); Mao, Liu, Zhang e Deng (2016); } \\
\text { Shinoda, Maximiano e Sbragia (2015); Monavvarian e } \\
\text { Kasaei (2007); Paula e Rover (2012); Riege e Lindsay } \\
\text { (2006); Scholl e Scholl (2014); Voronchuk e Starineca } \\
\text { (2014); Wiig (1997, 2002). }\end{array}$ \\
\hline $\begin{array}{l}\text { Qualidade na Tomada } \\
\text { de Decisáo do Gestor } \\
\text { Público }\end{array}$ & $\begin{array}{l}\text { Contribuição para participação do cidadão e organizações na Gestão } \\
\text { Pública; aumento da qualidade de vida através do desenvolvimento } \\
\text { do capital intelectual; alavancar os trabalhadores de conhecimento } \\
\text { na sociedade. Propiciar a tomada de decisão do gestor público } \\
\text { baseada em dados e informaçóes pertinentes acarretando vantagens } \\
\text { para a Administraçáo Pública: melhorar a prestação de serviços } \\
\text { públicos, superar desafios complexos, tornar a Gestão Pública mais } \\
\text { ágil, melhorar a eficácia das políticas e programas públicos. }\end{array}$ & $\begin{array}{l}\text { Gil-Garcia et al. (2013); Gil-Garcia et al. (2016); } \\
\text { Johnston e Hansen (2011); Monavvarian e Kasaei } \\
\text { (2007); Scholl e Scholl (2014); Wiig (2002). }\end{array}$ \\
\hline
\end{tabular}

Nota. Fonte: elaborado pelas autoras.

\section{PROCEDIMENTOS METODOLÓGICOS}

Considerando o objetivo da pesquisa em buscar caminhos que se demonstrem efetivos para maior Qualidade na Tomada de Decisão do Gestor Público, a partir do uso de elementos de Inteligência e Gestão do Conhecimento, primeiramente realizou-se uma revisão dos estudos já realizados, com base em três pilares principais: Gestão Pública, Gestão do Conhecimento e Inteligência. Com a revisão da literatura, foi possível a identificação dos elementos relativos à Gestão do Conhecimento, tais como criar, transformar, estruturar e compartilhar o conhecimento organizacional, e relativos à Inteligência, como o monitoramento do ambiente, identificação, organização e utilização de dados 
e informaçóes do ambiente, que permitiram montar o protocolo de pesquisa. Para a investigação empírica dentro de uma abordagem qualitativa e exploratória, optou-se pela realização de entrevistas semiestruturadas com uso de técnicas combinadas para a análise dos dados coletados: Análise de Conteúdo e Análise Comparativa Qualitativa (QCA).

\section{Coleta de dados}

De acordo com Myers (2013), pesquisadores qualitativos afirmam que é praticamente impossível entender por que alguém fez algo ou por que algo aconteceu em uma organização sem falar com as pessoas sobre isso. Assim, para o entendimento de como os gestores públicos aplicam os princípios dos processos de Gestáo do Conhecimento e Inteligência no desenvolvimento da atividade pública, optou-se pelo contato com pessoas envolvidas na tarefa, o que foi feito através da técnica de coleta de dados de entrevistas semiestruturadas.

A realização de entrevistas semiestruturadas com gestores públicos foi conduzida como o principal mecanismo de coleta de dados. O público-alvo desta pesquisa são gestores públicos efetivos (concursados) que exercem atividades de gestão junto a diversas secretarias de Estado vinculadas ao Poder Executivo de um dos estados do sul do Brasil. A escolha dos entrevistados deu-se por conveniência, aproximação e acessibilidade a servidores ocupantes de cargos de gerência e coordenação de órgãos públicos. Ao passo da realização das entrevistas, os gestores entrevistados indicavam outros que poderiam contribuir para a presente pesquisa. A partir da percepção de que a cada entrevista realizada náo havia novas contribuiçóes relevantes, e que respostas se repetiam, entendeu-se que o número de respondentes restava suficiente para a proposta do estudo.

Realizou-se entrevistas com 17 gestores públicos entre os meses de abril e maio de 2017, dos quais 15 (88\%) são do gênero masculino, 11 (65\%) estáo há mais de 10 anos no serviço público e 12 (71\%) recebem incentivo financeiro (produtividade) no órgão público em que trabalham. Ainda, $11(65 \%)$ possuem escolaridade de pós-graduação e desenvolvem atividades em diferentes áreas de atuação: fiscalização e cobrança, qualidade do gasto público, projetos e sistema, compras públicas, dentre outras áreas pertinentes ao desenvolvimento da atividade pública, conforme Tabela 2 .

Tabela 2. Perfil dos entrevistados.

\begin{tabular}{|c|c|c|c|c|c|}
\hline Entrevistado & $\begin{array}{c}\text { Tempo de } \\
\text { Serviço Público } \\
\text { (em anos) }\end{array}$ & Gênero & $\begin{array}{l}\text { Função no } \\
\text { Órgáo Público }\end{array}$ & Área de atuação & Escolaridade \\
\hline E1 & 10 & M & Gerente & Fiscalizaçáo e cobrança & Pós-graduaçáo \\
\hline E2 & 25 & M & Gerente & Projetos e sistemas & Pós-graduação \\
\hline E3 & 7 & M & Gerente & Qualidade do gasto público & Graduação \\
\hline $\mathrm{E} 4$ & 10 & M & Gerente & Programação orçamentária & Pós-graduação \\
\hline E5 & 25 & M & Diretor & Gestão administrativa & Mestrado \\
\hline E6 & 7 & M & Gerente & Planejamento financeiro e fluxo de caixa & Pós-graduação \\
\hline E7 & 23 & M & Gerente & Controle de dívidas públicas & Graduação \\
\hline E8 & 21 & M & Diretor & Projetos e sistemas & Pós-graduação \\
\hline E9 & 18 & M & Gerente & Desenvolvimento de pessoal & Graduação \\
\hline E10 & 7 & M & Gerente & Planejamento financeiro & Mestrado \\
\hline E11 & 25 & M & Diretor & $\begin{array}{c}\text { Desenvolvimento Organizacional e } \\
\text { Qualidade }\end{array}$ & Mestrado \\
\hline E12 & 39 & M & Gerente & Relações institucionais & Graduação \\
\hline E13 & 38 & M & Diretor & Compras públicas & Mestrado \\
\hline E14 & 6 & M & Gerente & Projetos e sistemas & Pós-graduação \\
\hline E15 & 8 & $\mathrm{~F}$ & Coordenador & Assessoria jurídica & Pós-graduação \\
\hline E16 & 2 & $\mathrm{~F}$ & Gerente & Desenvolvimento de pessoal & Graduação \\
\hline E17 & 36 & $\mathrm{M}$ & Gerente & Planejamento e modernizaçấo & Graduação \\
\hline
\end{tabular}

Nota. Fonte: elaborado pelas autoras. 
A partir da coleta dos dados, as entrevistas foram transcritas em sua totalidade, resultando em 92 páginas de dados brutos que foram organizados e estruturados, possibilitando a sistematização das ideias iniciais buscando analisar como a Gestão Pública entende e aplica elementos de Gestão do Conhecimento e Inteligência no desenvolvimento da atividade pública e para a maior Qualidade na Tomada de Decisão do Gestor Público. Depois, os referidos dados e informaçóes foram analisados através da associaçáo de duas técnicas: análise de conteúdo e análise comparativa qualitativa (QCA).

\section{Análise dos dados}

Para análise dos dados coletados, utilizou-se a técnica da análise de conteúdo associada à análise comparativa qualitativa através de conjuntos fuzzy. Inicialmente, baseando-se nos principais elementos apontados pelos entrevistados a partir da análise de conteúdo, estabeleceramse condiçóes que passaram pelo trabalho de calibração para a análise comparativa qualitativa, procedimentos e análises descritos na presente subseção.

\section{Análise de conteúdo}

A análise de dados seguiu as fases de análise elencadas no estudo de Bardin (2011). Após a transcrição dos dados, estes passaram por uma análise prévia que possibilitou a definição de categorias para análise dos dados coletados. A Tabela 3 apresenta a categorizaçáo dos dados para a análise de conteúdo, que se baseou na fundamentação teórica e na compreensão dos gestores públicos em relação aos processos de GC e Inteligência, seguida da estruturação e importância para o desenvolvimento da atividade pública. Além disso, foi possível verificar pontos convergentes de aproximação dos conceitos nos órgãos de análise e a evolução percebida na estruturação dos processos no setor público segundo a visão dos gestores públicos entrevistados.

Tabela 3. Categorização das informaçôes.

\begin{tabular}{|c|c|c|c|}
\hline $\begin{array}{l}\text { Informação } \\
\text { bruta }\end{array}$ & Categoria & Subcategoria & Suporte teórico \\
\hline \multirow{11}{*}{$\begin{array}{l}\text { Transcrição das } \\
\text { entrevistas }\end{array}$} & \multirow{3}{*}{$\begin{array}{l}\text { Gestão do } \\
\text { Conhecimento }\end{array}$} & $\begin{array}{l}\text { Processo de Gestão do } \\
\text { Conhecimento }\end{array}$ & \multirow{3}{*}{$\begin{array}{l}\text { Alavi e Leidner (2001); Davenport (1997); Gaspar et al. (2016); Gold et } \\
\text { al. (2001); Nonaka (1994); Nonaka e Konno (1998); Nonaka e Takeuchi } \\
\text { (2008); Wiig (1997, 2002). }\end{array}$} \\
\hline & & Criação do conhecimento & \\
\hline & & $\begin{array}{l}\text { Utilização, armazenamento e } \\
\text { disseminação do conhecimento }\end{array}$ & \\
\hline & \multirow{4}{*}{ Inteligência } & $\begin{array}{l}\text { Atividades e equipes de } \\
\text { Inteligência }\end{array}$ & \multirow{4}{*}{$\begin{array}{l}\text { Andriotti et al. (2008); Davenport (1998); Fachinelli et al. (2013); Janissek- } \\
\text { Muniz et al. (2006); Janissek-Muniz e Blanck (2014); Rios et al. (2011). }\end{array}$} \\
\hline & & Coleta de dados e informaçôes & \\
\hline & & $\begin{array}{c}\text { Análise e utilização de dados e } \\
\text { informações }\end{array}$ & \\
\hline & & $\begin{array}{l}\text { Disseminação de dados e } \\
\text { informaçôes na organizaçãoo }\end{array}$ & \\
\hline & \multirow{3}{*}{$\begin{array}{l}\text { Convergência } \\
\text { entre Gestáo do } \\
\text { Conhecimento } \\
\text { e Inteligência na } \\
\text { Gestão Pública }\end{array}$} & Apoio da alta gestão & $\begin{array}{l}\text { Gil-Garcia et al. (2013); Gil-Garcia et al. (2016); Hazlett et al. (2008); } \\
\text { Johnston e Hansen (2011); Lindner e Wald (2011); Monavvarian e Kasaei } \\
\text { (2007); Riege e Lindsay (2006); Scholl e Scholl (2014); Shinoda et al. } \\
\text { (2015); Wiig (2002). }\end{array}$ \\
\hline & & $\begin{array}{l}\text { Uso de tecnologia da informação } \\
\text { e comunicaçãao }\end{array}$ & $\begin{array}{l}\text { Alhamoudi (2015); Arora (2011); Dawes et al. (2009); Davenport (1998); } \\
\text { Gaspar et al. (2016); Gil-Garcia et al. (2013); Gil-Garcia et al. (2016); Gold } \\
\text { et al. (2001); Jain e Jeppesen (2013); Johnston e Hansen (2011); Mao et al. } \\
\text { (2016); Paula e Rover (2012); Pee e Kankanhalli (2016); Scholl \& Scholl, } \\
\text { 2014; Schutte e Barkhuizen (2015); Wiig (2002). }\end{array}$ \\
\hline & & Capital humano & $\begin{array}{l}\text { Arora (2011); Davenport (1998); Dawes et al. (2009); Gil-Garcia et al. } \\
\text { (2013); Gil-Garcia et al. (2016); Johnston e Hansen (2011); Mao et al. } \\
\text { (2016); Monavvarian e Kasaei (2007); Paula e Rover (2012); Scholl \& } \\
\text { Scholl, 2014; Voronchuk e Starineca (2014); Wiig (1997, 2002). }\end{array}$ \\
\hline & $\begin{array}{l}\text { Qualidade na } \\
\text { Tomada de Decisão } \\
\text { do Gestor Público }\end{array}$ & - & $\begin{array}{l}\text { Gil-Garcia et al. (2013); Gil-Garcia et al. (2016); Johnston e Hansen (2011) } \\
\text { Monavvarian e Kasaei (2007); Scholl e Scholl (2014); Wiig (2002). }\end{array}$ \\
\hline
\end{tabular}

Nota. Fonte: elaborado pelas autoras. 
Em relaçáo à influência de elementos dos processos de GC e de Inteligência para maior Qualidade na Tomada de Decisão do Gestor Público, todos os dezessete entrevistados são categóricos em elencar dados do ambiente externo, informação e conhecimento produzido pela organizaçáo como de suma importância e definitivos para a qualidade da tomada de decisão, mesmo não havendo uma estruturação dos referidos processos. Tal posicionamento dos entrevistados vai ao encontro do exposto da teoria sobre o tema, tanto em relação ao compartilhamento de conhecimento entre a base e o topo de gestáo como na busca de dados e informaçóes pertinentes e que qualifiquem a tomada de decisão do gestor no sentido de superar desafios complexos da Administração Pública (Wiig, 2002; Johnston \& Hansen, 2011; Gil-Garcia et al., 2013).

Um dos elementos elencados por um dos entrevistados diz respeito à necessidade de as decisóes estarem se tornando cada vez mais rápidas, consistentes e transparentes (Riege \& Lindsay, 2006), ressaltando que "caso não se utilizasse de dados e informaçóes do ambiente, o processo de decisão ficaria muito dependente, talvez subjetivo, influenciável por capacidade de pressão de um gestor ou outro, outras não estariam tão claras". Outra questão que merece atenção diz respeito ao desenvolvimento de capacidades analíticas para que servidores possam processar os dados e informaçóes e avançar na tomada de decisáo baseada em evidências (Malomo \& Sena, 2017; Valle-Cruz \& Sandoval-Almazan, 2018). Um gestor público entrevistado considera que há muito a melhorar em relação a uma maior preocupação com o uso de dados e informaçóes para a Qualidade na Tomada de Decisão do Gestor Público no desenvolvimento de políticas públicas. Além disso, acrescenta que "um processo mais estruturado de Gestão do Conhecimento é uma carência, às vezes preciso de uma informação sobre algo e eu preciso ligar, ficando atrelado às relaçóes interpessoais".

A partir das questóes que emergiram na categorização das informaçôes via análise de conteúdo, e objetivando a complementaçáo do estudo por meio do mapeamento de configuraçôes causais relativas aos princípios de Gestáo do Conhecimento e Inteligência que potencialmente possam conduzir à Qualidade na Tomada de Decisão do Gestor Público, optou-se pela aplicação da técnica de análise de dados QCA - qualitative comparative analysis, utilizando conjuntos fuzzy. A próxima seção é composta pelo desenvolvimento da referida análise.

\section{Análise comparativa qualitativa}

A aplicação da técnica fuzzy-set qualitative comparative analysis, também conhecida como análise comparativa qualitativa, mostra-se efetiva para o desenvolvimento deste trabalho, uma vez que a partir da sua utilização é possível identificar configuraçóes causais que conduzem à presença ou à ausência (a ausência é representada pelo símbolo ) de um determinado resultado, podendo apresentar mais de uma solução para cada objetivo (Rihoux \& Ragin, 2009). A análise QCA através de conjuntos fuzzy (fuzzy set) permite, a partir da inserção de valores de associaçáo entre 0 e 1 , uma percepçáo mais aproximada das situaçóes estudadas (Ragin, 2000).

Como resultado da análise fsQCA, foi possível identificar quais configuraçôes de condiçôes causais conduzem à Qualidade na Tomada de Decisão do Gestor Público, bem como a ausência do respectivo resultado. Cada configuração das condiçóes causais e o resultado associado são designados como um caso (Fiss, 2007). As condiçóes causais na análise fsQCA estão relacionadas às dimensóes que se demonstraram importantes, a partir do referencial teórico e da análise do conteúdo das entrevistas, em relação à utilização de processos de Gestáo do Conhecimento e Inteligência no contexto da Gestáo Pública.

As condiçóes relacionadas à maior Qualidade na Tomada de Decisão do Gestor Público são a utilização de processos de Gestão do Conhecimento $(g c)$, Inteligência (intel) e o Apoio da Alta Gestáo (altagest) e a influência do tempo de serviço público (temp) e gênero do entrevistado (gen). As dimensões relacionadas ao uso de TIC e a participação das pessoas não foram analisadas na aplicação da metodologia por se mostrarem, a partir do referencial e das entrevistas, necessárias em ambos os casos, não havendo necessidade de incorporar no estudo como forma de trazer um diferencial para a pesquisa.

\section{Calibração de condições}

Em sua origem, QCA foi desenvolvida para a análise de configuraçóes de conjuntos booleanos convencionais, ou seja, para analisar se uma determinada variável é membro ou não de um dado conjunto, através da definição de conjuntos crispy (conjuntos de condiçóes que só assumem valores 0 e 1 ). QCA utiliza conjuntos crispy (csQCA), o que possibilita ao investigador conjuntos com dados simples compostos de variáveis binárias, codificadas como 1 para 'presente' e 0 para 'ausente' (Rihoux \& Ragin, 2009). O presente estudo possui a condição 'gênero' classificada com variável binária.

Além de trabalhar com variáveis binárias existentes na abordagem de conjunto tradicional, o fsQCA (usa conjuntos fuzzy) também permite usar valores de associação entre $0 \mathrm{e}$ 1 , e não somente 0 ou 1 . O fsQCA aceita configuraçóes alternativas de condiçóes, equifinalidade e assimetria (Fiss, 2007), ou seja, os conjuntos fuzzy permitem a percepção muito mais detalhada e aproximada das situaçóes estudadas (Ragin, 2000). Segundo o autor, o mais importante é a ligação entre a teoria e dados de análise nas ciências sociais, o que pode ser aprimorado utilizando conjuntos fuzzy, 
uma vez que estes podem ser desenhados para se ajustar e 'preencher' conceitos teóricos.

A calibração é o processo de classificação de condiçôes em cada caso, desde a adesão total $(1,00)$ até a total não adesão $(0,00)$, e implica um conhecimento teórico e empírico sobre as variáveis (Ragin, 2005; 2008). No presente estudo foram utilizadas variáveis binárias e variáveis categóricas calibradas para permitir o uso de fsQCA, em que cada categoria foi associada a um grupo significativo (associação total, ponto de máxima ambiguidade e não associação total). Para calibrar os dados dos fuzzy sets pode-se utilizar um procedimento mecânico (baseado na teoria) ou um procedimento manual (baseado em evidências). Neste estudo, optou-se pela calibração das condiçóes causais e os resultados de forma manual, com base na análise das entrevistas realizadas com gestores públicos.

Em relação aos processos de Inteligência e GC, optouse por computar os diversos procedimentos pertencentes a cada processo, para fins de posterior análise. Desta forma, a variável Inteligência (intel) é compreendida pela união de pelo menos uma das variáveis pertencentes ao processo (monitoramento do ambiente, utilização de informaçóes ou disseminação interna de dados e informaçóes). Da mesma maneira, estabeleceu-se a variável Gestáo do Conhecimento $(g c)$ por meio da uniáo de pelo menos uma das variáveis pertencentes ao processo (criação de conhecimento, armazenamento de conhecimento, utilização de conhecimento ou disseminação de conhecimento).

Para as variáveis $g c$, intel e Apoio da Alta Gestáo (apoiogest), o processo de calibração se estabeleceu a partir da definição de níveis de importância dos respectivos processos e apoio, ou seja, utilizou-se 0,00 para processo/apoio não importante; 0,25 para processo/apoio minimamente importante; 0,50 para processo/apoio mediamente importante; 0,75 para processo/apoio consideravelmente importante; e 1,00 para processo/apoio totalmente importante. $\mathrm{O}$ uso de abreviaçôes para as variáveis permite auxiliar no entendimento e descrição das configuraçóes causais.

A variável Tempo de Serviço Público (temp) apresenta vários valores, e compóe uma base de dados fuzzy (fuzzy set). As variáveis com valores fuzzy apresentam o grau com que diferentes casos pertencem a um determinado conjunto, avaliando diferentes graus de associação entre a plena inclusão e a exclusão total. Tal calibração só é possível a partir do uso de conhecimento teórico e substantivo, que é essencial para a especificação dos três pontos de interrupçáo qualitativos: adesão plena, não adesão plena, e ponto de máxima ambiguidade sobre a adesão (Ragin, 2005). Desta forma, temos na adesão plena $(0,90)$ o tempo de 39 anos de serviço público; na não adesão plena $(0,10)$, o tempo de dois anos de serviço público; e no ponto de máxima ambiguidade $(0,50)$, o tempo de 14 anos de serviço público.

Gênero (gen) é uma variável binária. Em relação ao resultado Qualidade na Tomada de Decisão do Gestor Público, o processo de calibração foi estabelecido através da definição dos níveis de importância: 0,00 (inexistência de qualidade); 0,25 (má qualidade); 0,50 (qualidade média); 0,75 (muita qualidade); 1,00 (qualidade total). A Tabela 4 demonstra os cortes utilizados na calibração para as condiçóes causais; para cada condição apresenta-se a calibraçáo usada neste estudo.

Tabela 4. Calibraçáo de condiçôes (variáveis).

\begin{tabular}{cc}
\hline Condiçóes e objetivo & Calibração \\
\hline Gestão do Conhecimento $(g c)$ & $(0,00 ; 0,25 ; 0,50 ; 0,75 ; 1,00)$ \\
Inteligência (intel) & $(0,00 ; 0,25 ; 0,50 ; 0,75 ; 1,00)$ \\
Apoio da Alta Gestão (altgest) & $(0,00 ; 0,25 ; 0,50 ; 0,75 ; 1,00)$ \\
Tempo de Serviço Público (temp) & $(39 ; 14 ; 2)$ \\
Gênero (gen) & Variável binária: $0=$ Masculino; $1=$ Feminino \\
Qualidade na Tomada de Decisão (quali) & $(0,00 ; 0,25 ; 0,50 ; 0,75 ; 1,00)$ \\
\hline
\end{tabular}

Nota. Fonte: elaborado pelas autoras. Calibraçáo é o processo de classificaçâo de condiçốes em cada caso, desde a adesão total $(1,00)$ até a total não adesão $(0,00)$, e implica um conhecimento teórico e empírico sobre as variáveis (Ragin, 2005; 2008).

\section{Análise de condições necessárias}

As condiçóes causais são avaliadas na sua necessidade e suficiência. O grau de necessidade da condição causal indica a medida em que ela é necessária para alcançar um determinado resultado. Em relação ao grau de suficiência da condiçấo causal, este demonstra a extensão em que ele pode ser relacionado à explicação dos resultados (Fiss, Sharapov, \&
Conqvist, 2013). Para Ragin (2000), as condiçóes necessárias devem apresentar valores de consistency que ultrapassem o limite de 0,80 . Em relaçáo ao objetivo da presente análise, ao abordar as condiçóes necessárias para a Qualidade na Tomada de Decisão do Gestor Público temos que homens $(\sim g e n)$, Apoio da Alta Gestão (apoiogest), Gestão do Conhecimento $(g c)$ e Inteligência (intel) possuem consistency superior a 0.90, demonstrando a referida importância. Em 
relação às condiçóes necessárias para a ausência do resultado, ou seja, para a ausência de Qualidade na Tomada de Decisão do Gestor Público, os resultados apontam que a ausência de Apoio da Alta Gestão ( altagest) e a ausência de Gestão do Conhecimento $(\sim g c)$ sáo representativas, apresentando consistency superior a 0.90 .

\section{Análise das configurações causais}

Seguindo as melhores práticas da literatura, para os resultados da análise de suficiência serão reportadas as soluções intermediárias que não são as mais rigorosas (denominadas de parcimoniosas) e nem as menos rigorosas (denominadas de complexas) (Fiss, 2011; Ragin, 2008). As soluções são conjuntos de configurações causais de condiçôes que indicam os caminhos alternativos que levam ao resultado em análise. Existem condições centrais e condições periféricas. As condições centrais são aquelas que estâo presentes tanto nas soluçôes parcimoniosas quanto nas intermediárias; as condiçóes periféricas, por sua vez, estão presentes apenas nas soluções intermediárias (Ragin, 2000, 2008; Fiss, 2011; Fiss et al., 2013). Visando a uma melhor compreensão, cabe ressaltar que as soluçóes parcimoniosas possuem apenas as condiçóes centrais que estão altamente ligadas ao resultado, enquanto as intermediárias são mais conservadoras e assumem as hipóteses simplificadas mais plausíveis (Ragin, 2008).
Em relaçáo à Qualidade na Tomada de Decisão do Gestor Público, os resultados da análise de suficiência mostram uma solução intermediária com uma única configuração com consitency acima de 0,80 cumprindo com o limiar sugerido por Ragin (2008). Já em relação à ausência de Qualidade na Tomada de Decisão do Gestor Público, a solução intermediária mostra três configuraçóes causais com consistency acima de 0,89 , ou seja, respeitando a regra de ser superior a 0,80 sugerida por Ragin (2008) ou Fiss (2011). Tal diferença na quantidade de configuraçóes causais para maior Qualidade na Tomada de Decisão do Gestor Público e referida ausência demonstram-se como um resultado importante do estudo.

As configuraçóes causais apresentadas na Tabela 5 apresentam as condiçóes centrais (core conditions) e periféricas, tanto para o resultado Qualidade na Tomada de Decisão do Gestor Público (quali) quanto para a ausência de Qualidade naTomada de Decisão do Gestor Público ( quali). Em relação à Qualidade na Tomada de Decisão do Gestor Público, a solução intermédia oferece uma única configuração. No que diz respeito à ausência de Qualidade na Tomada de Decisão do Gestor Público, a respectiva solução parcimoniosa mostra três configuraçóes causais intermediárias. Devem ser considerados, na Tabela 5, intel = Inteligência; $g c=$ Gestão do Conhecimento; apoiogest $=$ Apoio da Alta Gestão; gen = Gênero; temp = Tempo de Serviço Público.

Tabela 5. Configurações causais.

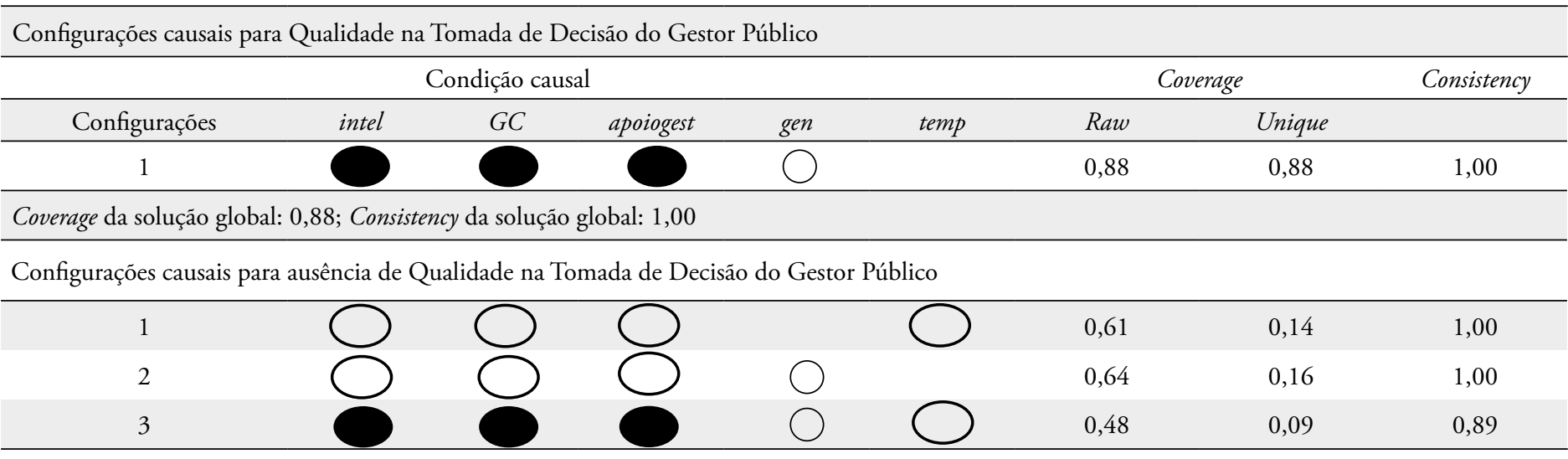

Coverage da solução global: 0,86; Consistency da solução global: 0,93

Nota. Fonte: elaborado pelas autoras. Círculos pretos cheios $(\bullet)$ indicam a presença da condição. Círculos não preenchidos ( ) indicam a ausência da condição. Círculos grandes indicam condições centrais. Círculos pequenos descrevem condiçóes periféricas. Espaços em branco indicam que a condição não contribui.

A partir da análise das configuraçóes é possível depreender que o fsQCA permite que as variáveis possam estar casualmente relacionadas em uma configuração sem necessariamente estarem relacionadas, ou mesmo inversamente relacionadas, em outras configurações; ou seja, pode haver configuraçóes alternativas de condiçóes causais tanto para a presença quanto para a ausência em relação ao resultado esperado, sendo que tais configuraçóes refletem as três características do fsQCA: (a) mais do que uma configuração de condições causais conduz ao resultado e à sua ausência (configurações alternativas de condiçóes causais); (b) as configuraçôes causais alternativas podem 
produzir o mesmo resultado (equifinalidade); (c) condições causais do resultado podem diferir das condiçóes causais da sua ausência (assimetria).

É possível depreender, a partir da leitura da Tabela 5, que a análise fsQCA produziu apenas uma configuração causal que conduz à Qualidade na Tomada de Decisão do Gestor Público. Tal configuração, advinda da solução intermediária, demonstra que a combinação de processos de Inteligência, GC, Apoio da Alta Gestão e o gestor do gênero masculino levam a uma maior Qualidade na Tomada de Decisão do Gestor Público. Em relação às duas primeiras configuraçóes apresentadas pela fsQCA, quanto à ausência de Qualidade na Tomada de Decisão do Gestor Público, estão simétricas aos resultados obtidos junto à configuraçáo para a Qualidade na Tomada de Decisão do Gestor Público. Estes resultados são coerentes em relação ao exposto a partir da análise de conteúdo reportada. A aplicação conjunta de duas técnicas de análise de dados - análise de conteúdo e análise comparativa qualitativa - demonstrou-se relevante para o desenvolvimento do estudo, permitindo complementar e validar a investigaçáo realizada. Os resultados obtidos a partir da análise de configuraçóes causais demonstram estar de acordo com o apresentado na análise de conteúdo, bem como em relação ao levantamento teórico realizado para a presente pesquisa, conforme apresentado na subseção seguinte.

\section{Validação dos resultados}

Uma análise qualitativa de conteúdo deve ser avaliada com base na confiabilidade e validade (Duriau, Reger, \& Pfarrer, 2007). No entanto, "a pesquisa qualitativa deve ser julgada e avaliada de acordo com critérios diferentes daqueles utilizados pelos pesquisadores quantitativos" (Bryman \& Bell, 2003, p. 411). Garantimos a validade seguindo os princípios de confiabilidade e autenticidade emprestados do construtivismo (Guba \& Lincoln, 2005). A confiabilidade engloba quatro critérios equivalentes aos da pesquisa quantitativa (Bryman \& Bell, 2003): "credibilidade (que é paralela à validade interna), transferibilidade (que é paralela à validade externa), confiabilidade (que é paralela à confiabilidade) e confirmabilidade (que é paralela à objetividade)" (Bryman \& Bell, 2003, p. 411).

Para o presente estudo, foram realizadas 17 entrevistas gravadas digitalmente em áudio e transcritas literalmente. As entrevistas permitiram desenvolver completamente a compreensão do fenômeno pesquisado, validando a revisão de literatura. A análise inicial dos dados coletados com as entrevistas iniciou pela identificação de conceitos relevantes nos dados e agrupando-os em categorias (codificação aberta). A codificação aberta envolve examinar, comparar, conceituar e categorizar os dados. O processo de codificação aberta gera conceitos que podem ser posteriormente agrupados em categorias (Bryman \& Bell, 2003, p. 586). Aplicamos a codificação aberta associando códigos e criando categorias e relacionamentos entre eles. Uma classificação única foi usada para cada código, o que significa que as categorias eram mutuamente exclusivas, conforme recomendado por Weber (1990), para restringir as categorias aos códigos que os refletem inconfundivelmente, o que maximiza a validade.

A garantia da autenticidade (Guba \& Lincoln, 2005) estabeleceu-se a partir da participação de vários gestores públicos com diferentes tempos de serviço público, diferentes funçôes no órgão público, diferentes áreas de especialidade e diferentes gêneros. Assim, foi fornecida autenticidade ontológica, produzindo e oferecendo às organizaçóes públicas um modelo que esclarece o racional da qualidade do processo de tomada de decisão do gestor público. Essa contribuiçáo envolve a configuração causal para Qualidade na Tomada de Decisão do Gestor Público e as configuraçóes causais para ausência de Qualidade na Tomada de Decisão do Gestor Público.

A validade da análise de conteúdo foi avaliada com base na saturação dos dados (Finfgeld-Connett, 2014). Nos estudos qualitativos, a amostragem deve ser intencional. $\mathrm{O}$ método de amostragem usa amostragem propositiva, também conhecida como amostragem julgadora, seletiva ou subjetiva; é uma forma de amostragem não probabilística, na qual os pesquisadores confiam em seu próprio julgamento ao escolher membros da população para participar de seu estudo. As entrevistas decorrem até a saturação teórica, ou seja, quando há melhorias triviais e o fenômeno se torna repetitivo (Finfgeld-Connett, 2014). Desta forma, o tamanho da amostra depende da participação suficiente para alcançar a saturaçáo teórica. Após a $17^{\mathrm{a}}$ entrevista entendeuse o alcance da saturação teórica (Glaser \& Strauss, 1967), ou seja, não surgiram novos códigos.

A validade da análise fsQCA foi alcançada pela confirmação das configuraçóes pelos dados, por exemplo: foram encontrados exemplos da configuração para Qualidade na Tomada de Decisão do Gestor Público na entrevista do entrevistado (E8): "a informação e o conhecimento produzido a partir de dados do ambiente qualificam a tomada de decisão. Eles influenciam porque trazem elementos que podem ser adicionais, complementares, para que se possa fazer uma melhor avaliação de um determinado cenário que está se colocando para a tomada de decisão". Ainda, tal resultado vai ao encontro do exposto na teoria sobre a temática, a qual aponta a importância da Gestão do Conhecimento e da busca por dados e informaçóes pertinentes que qualifiquem a tomada de decisão na busca por superar desafios complexos em governo (Gil-Garcia et al., 2013; Johnston \& Hansen, 2011; Wiig, 2002).

Da mesma forma, foi possível validar as configuraçôes causais para ausência de Qualidade na Tomada de Decisão 
do Gestor Público. Como exemplo para as referidas configuraçóes, tem-se a situação apontada pelo entrevistado E10: "muitas decisões acabam tendo o viés político e não baseado em dados, informaçóes e conhecimento, o que acarreta ausência de qualidade decisória”. Da mesma forma, o entrevistado E11 aponta que muitos gestores públicos reconhecem ter as informaçóes para qualificar a decisão, mas estas nem sempre são utilizadas.

Ainda, cabe ressaltar: em relação à análise da terceira configuração causal foi possível verificar que, para um gestor do gênero masculino, com pouco tempo de serviço público, mesmo com Apoio da Alta Gestão, os processos de Inteligência e de Gestão do Conhecimento apresentam-se como insuficientes para a Qualidade na Tomada de Decisão do Gestor Público. Tal resultado demonstra uma questão potencial a ser mais bem explorada em estudos futuros, uma vez que nem a revisão teórica, nem a análise de conteúdo trouxeram questóes relacionadas a gênero e tempo de serviço, podendo mesmo haver influência de outras condiçóes não avaliadas.

\section{DISCUSSÕES}

A partir do embasamento teórico, especificaramse aspectos relevantes em relaçáo ao uso de Gestáo do Conhecimento e Inteligência no contexto público, a partir dos quais foram identificadas questóes relacionadas ao apoio da alta gestáo, uso de TICs e participaçáo das pessoas como elementos que aproximam os conceitos de Gestáo do Conhecimento e Inteligência na Gestão Pública. Observase que a associação e aplicação de processos de Gestão do Conhecimento e Inteligência na Gestão Pública visam, dentre outros aspectos, a uma maior qualidade na tomada de decisão.

A partir da análise dos dados coletados com os gestores públicos, foi possível: identificar aspectos de complementaridade dos conceitos de Gestão do Conhecimento e Inteligência segundo a visão de gestores públicos; verificar a percepçáo de gestores públicos quanto à importância dos referidos processos no contexto público; analisar a existência de processos estruturados de Gestão do Conhecimento e Inteligência na gestão pública; e, por fim, identificar caminhos que se demonstram efetivos para maior Qualidade na Tomada de Decisão do Gestor Público. Tal objetivo vai ao encontro do exposto em relação à tendência de uma Administração Pública mais participativa, eficiente, integrada em rede e que propicie uma melhor Gestão Pública na entrega de serviços à sociedade (Capobiango et al., 2013; Paula, 2005; Secchi, 2009). Os gestores públicos entrevistados reconhecem a importância de tais processos para a qualificação da tomada de decisão.
Entretanto, apesar de reconhecerem a importância dos processos de Gestão do Conhecimento e Inteligência para a Gestão Pública, nota-se a inexistência de processos estruturados de Gestáo do Conhecimento junto aos órgáos públicos participantes da pesquisa. Identificam-se algumas experiências isoladas de utilização de pressupostos do processo, mas o conhecimento, no geral, ainda se encontra enraizado nas pessoas e seu compartilhamento se estabelece a partir das relaçóes sociais entre os servidores. Tal pressuposto demonstra-se como preocupante para a Gestão Pública, haja vista que não há estruturação do conhecimento e este está atrelado a questóes de relaçóes para a sua disseminação (Eom et al., 2016; Gil-Garcia et al., 2016; Johnston \& Hansen, 2011; Riege \& Lindsay, 2006; Scholl \& Scholl, 2014).

Ainda, cabe ressaltar que há o recebimento por parte da Gestáo Pública de uma grande quantia de dados e informaçóes do ambiente e que, conforme os entrevistados, não há recursos de pessoal suficientes para realizar a análise de dados e informaçóes que envolvem demandas menores da população e/ou irregularidade com pouco impacto social e/ou financeiro para o Estado. Este ponto demonstra-se como algo a que deve ser dada maior atenção por parte da alta Gestáo Pública, uma vez que podem estar contidos importantes insights quanto aos anseios da sociedade em relação ao desenvolvimento de políticas públicas.

A partir da análise comparativa qualitativa, identificaram-se caminhos que levam à Qualidade na Tomada de Decisão do Gestor Público através do uso e da ausência de processos de Gestão do Conhecimento e Inteligência. Tal análise demonstrou-se ir ao encontro do exposto na revisão teórica e na análise de conteúdo, uma vez que se identificou que os processos de Gestão do Conhecimento e de Inteligência juntamente com os demais fatores analisados levam a uma maior Qualidade na Tomada de Decisão do Gestor Público.

O fato de o estudo ter demonstrado três configuraçôes causais para ausência de Qualidade na Tomada de Decisão do Gestor Público apresenta-se como uma oportunidade a ser mais bem investigada em estudos futuros, principalmente em relação à influência de gênero e tempo de serviço público dos gestores. A ausência de tempo de serviço apresenta-se em duas das três configuraçóes que levam à ausência de Qualidade na Tomada de Decisão do Gestor Público, entretanto, o estudo não conseguiu identificar a causa, uma vez que pode estar relacionada tanto à falta de formação quanto à falta de conhecimento tácito da organizaçáo e procedimentos, ambos adquiridos com o tempo de organização.

Ainda, pode-se considerar, em estudos futuros, a possibilidade de existirem condiçóes que não foram trabalhadas no presente estudo e que possam influenciar a Qualidade na Tomada de Decisão do Gestor Público. Condiçóes como treinamento e desenvolvimento de pessoal 
podem ser um caminho interessante a ser estudado. Por fim, ressalta-se que a utilização de duas técnicas de análise de dados (análise de conteúdo e análise comparativa qualitativa) demonstrou-se interessante para o desenvolvimento de pesquisas qualitativas, uma vez que a partir da análise com a utilização das duas técnicas foi possível complementar e validar a análise realizada.

\section{CONSIDERAÇÕES FINAIS}

Este estudo fornece uma contribuição original não abordada na literatura, pois apresenta as configuraçóes causais que levam à Qualidade na Tomada de Decisão do Gestor Público (bem como as configuraçóes causais que levam à ausência de tal resultado) utilizando elementos das teorias de Gestão do Conhecimento e Inteligência no contexto da Gestão Pública brasileira. As descobertas mostram um caminho que leva à qualidade na tomada de decisões e três que levam à sua ausência. Tais achados demonstram a importância do uso de elementos dos processos de Gestáo do Conhecimento e Inteligência para maior qualidade nas decisões da Administração Pública, uma vez que dados, informaçóes e conhecimentos possibilitam tomadas de decisão valiosas para os gestores públicos em relação às políticas públicas a serem adotadas ou mantidas para atender os objetivos junto à sociedade.

Um dos principais benefícios de se conhecer os caminhos que levam a uma maior Qualidade na Tomada de Decisão do Gestor Público está em apontar uma alternativa de processos a serem desenvolvidos junto aos órgáos públicos na

\section{REFERÊNCIAS}

Abrucio, F. L. (1997). O impacto do modelo gerencial na administraçáo pública: um breve estudo sobre a experiência internacional recente. Brasília, DF: ENAP. Retrieved from https://repositorio.enap.gov.br/bitstream/1/556/1/O\%20 impacto\%20do\%20modelo\%20gerencial\%20na\%20 Administra\%c3\%a7\%c3\%a3o\%20P\%c3\%bablica.pdf

Alavi, M., \& Leidner, D. E. (2001). Knowledge management and knowledge management systems: Conceptual foundations and research issues. MIS Quarterly, 25(1), 107-136. https://doi.org/10.2307/3250961

Alhamoudi, S. (2015). Knowledge Management Strategies in Public Sector-CaseStudy. China-USABusinessReview, 14(3), 159170. http://doi.org/10.17265/1537-1514/2015.03.004 construção de uma Gestão Pública mais efetiva. Entretanto, cabe ressaltar que quando um dos caminhos é atendido, fazse necessário mantê-lo e buscar novos caminhos que possam se demonstrar eficazes para os resultados desejados pela Administração. Quanto ao benefício em saber os caminhos que levam à ausência de uma maior Qualidade na Tomada de Decisão do Gestor Público, temos a oportunidade de evitar tais configuraçóes nas organizaçóes públicas, de modo a evitar a tomada de decisão não adequada.

O presente estudo traz uma nova forma de analisar condiçóes e propor um caminho suficiente para levar a uma maior Qualidade na Tomada de Decisão do Gestor Público. Estudos futuros podem focar na questáo da influência do gênero e tempo de serviço público na tomada de decisão de gestores públicos, uma vez que os resultados demonstraram que pode haver uma relação entre gênero e tempo de serviço com aspectos de confiança quando da tomada de decisão dos gestores públicos, independentemente da utilização de processos estruturados de gestão.

Ainda, para pesquisas futuras, sugerimos a análise comparativa entre órgáos públicos que possuem processos de Gestão do Conhecimento e Inteligência estruturados com os que náo os possuem como meio de analisar os fatores determinantes de sucesso na implantação e desenvolvimento de tais processos como meio de auxiliar a maior Qualidade na Tomada de Decisão do Gestor Público. Além disso, o presente estudo pode ser replicado na esfera empresarial (empresas grandes e pequenas, familiares e multinacionais, bem como em organizaçóes sem fins lucrativos).

Andriotti, F. K., Freitas, H., \& Janissek-Muniz, R. (2008). Informação informal e a monitoraçâo do ambiente organizacional: reflexóes e sugestóes para a área de TI. III Prêmio de INovação em Inteligência Competitiva. Congresso Ibero Americano de Gestão do Conhecimento e Inteligência Competitiva, Brasília, DF. Brazil. 2.

Arora, E. (2011). Knowledge management in public sector. Researchers World, 2(1), 165. Retrieved from http://citeseerx.ist.psu.edu/viewdoc/ download?doi=10.1.1.474.3542\&rep=rep1\&type=pdf

Bardin, L. (2011). Análise de conteúdo. Lisboa: Ediçôes, 70. 
Batista, F. F. (2012). Modelo de gestão do conhecimento para a administração pública brasileira: como implementar a gestão do conhecimento para produzir resultados em beneficio do cidadão. Brasília, DF: Ipea, 2012. Retrieved from https:// www.ipea.gov.br/portal/images/stories/PDFs/livros/ livros/livro modelodegestao vol01.pdf

Benedetti, F., \& Janissek-Muniz, R. (2009). Knowledge management: an important resource for the strategic intelligence. Anais do CONTECSI - International Conference on Information Systems and Technology Management, São Paulo, SP, Brazil, 6.

Bernardes, M. B., Andrade, F. P. de, Novais, P., \& Lopes, N. V. (2017). Reference model and method of evaluation for smart cities in government portals: a study of the Portuguese and Brazilian reality. Proceedings of the International Conference on Electronic Governance and Open Society: Challenges in Eurasia. ACM. https://doi.org/10.1145/3129757.3129781

Bryman, A., \& Bell, E. (2003). Business Research Methods. Hong Kong: Oxford University Press.

Capobiango, R. P., Nascimento, A. D. L. do, Silva, E. A., \& Faroni, W. (2013). Reformas administrativas no Brasil: Uma abordagem teórica e crítica. REGE Revista de Gestão, 20(1), 61-78. https://doi.org/10.5700/rege487

Cavalcante, P. (2018). Innovations in the Federal Government during the post-new public management era. Revista de Administração Contemporânea, 22(6), 885-902. https://doi.org/10.1590/1982-7849rac2018170391

Cepik, M. A. (1997). Inteligência, política e poder no Estado contemporâneo. Revista de Sociologia e Politica, (9), 193196. Retrieved from http://professor.ufrgs.br/marcocepik/ publications/inteligencia-politica-e-poder-no-estadocontemporaneo-resenha

Cepik, M. (2005). Regime político e sistema de inteligência no Brasil: legitimidade e efetividade como desafios institucionais. Dados, 48(1), 67-113. https://doi.org/10.1590/S0011-52582005000100004

Davenport, T. H. (1997). Ten principles of knowledge management and four case studies. Knowledge and process Management, 4(3), 187-208. https://doi.org/10.1002/(SICI)10991441(199709)4:3<187::AID-KPM99>3.0.CO;2-A

Davenport, T. H. (1998). Ecologia da informação: Porque só a tecnologia não basta para o sucesso na era da informação. São Paulo: Futura.

Dawes, S. S., Cresswell, A. M., \& Pardo, T. A. (2009). From "need to know" to "need to share": Tangled problems, information boundaries, and the building of public sector knowledge networks. Public Administration Review, 69(3), 392-402. https://doi.org/10.1111/j.1540-6210.2009.01987 2.x
Desouza, K. C. (2005). Restructuring government intelligence programs: A few good suggestions. Government Information Quarterly, 22(3), 342-353. https://doi.org/10.1016/j.giq.2005.05.001

Duriau, V. J., Reger, R. K., \& Pfarrer, M. D. (2007). A content analysis of the content analysis literature in organization studies: research themes, data sources, and methodological refinements. Organizational Research Methods. 10(1), 5-34. https://doi.org/10.1177/1094428106289252

Eom, S. J., Choi, N., \& Sung, W. (2016). The use of smart work in government: Empirical analysis of Korean experiences. Government Information Quarterly, 33(3), 562-571. https://doi.org/10.1016/j.giq.2016.01.005

Fachinelli, A. C., Glacomello, C. P., Rech, J., \& Bertolini, A. L. (2013). Inteligência estratégica: desenvolvimento de uma escala para compreensão do construto. Revista Brasileira de Estratégia, 6(2), 179-191. https://doi.org/10.7213/rebrae.06.002.AO06

Finfgeld-Connett, D. (2014). Use of content analysis to conduct knowledge-building and theory-generating qualitative systematic reviews. Qualitative Research, 14(3), 341-352. https://doi.org/10.1177/1468794113481790

Fiss, P.C. (2007). A set-theoretic approach to organizational configurations. Academy of Management Review, 32(4), 1180-1198. Retrieved from https://pdfs.semanticscholar. org/901b/357c7d4ab59298bd0872554f3f34091c40ff. pdf

Fiss, P. C. (2011). Building better causal theories: A fuzzy set approach to typologies in organization research. Academy of Management Journal, 54(2), 393-420. https://doi.org/10.5465/amj.2011.60263120

Fiss, P. C., Sharapov, D., \& Cronqvist, L. (2013). Opposites attract? Opportunities and challenges for integrating large-N QCA and econometricanalysis. PoliticalResearch Quarterly, 66(1), 191-198. https://doi.org/10.1177/1065912912468269e

Gaspar, M. A., Santos, S. A. dos, Donaire, D., Kuniyoshi, M. S., \& Prearo, L. C. (2016). Gestão do conhecimento em empresas atuantes na indústria de software no Brasil: um estudo das práticas e ferramentas utilizadas. Informação \& Sociedade, 26(1), 151-166. Retrieved from http://hdl.handle.net/20.500.11959/brapci/91930

Gil-Garcia, J. R., Pardo, T. A., \& Aldama-Nalda, A. (2013). Smart cities and smart governments: Using information technologies to address urban challenges. Proceedings of the 14 th Annual International Conference on Digital Government Research. https://doi.org/10.1145/2479724.2479728

Gil-Garcia, J. R., Helbig, N., \& Ojo, A. (2014). Being smart: Emerging technologies and innovation in the public sector. Government Information Quarterly, 31, I1-I8. https://doi.org/10.1016/j.giq.2014.09.001

Gil-Garcia, J. R., Zhang, J., \& Puron-Cid, G. (2016). Conceptualizing smartness in government: An integrative and multi-dimensional view. Government Information Quarterly, 33(3), 524-534. https://doi.org/10.1016/j.giq.2016.03.002 
Glaser, B. G., \& Strauss, A. L. (1967). The discovery of grounded theory: Strategies for qualitative research. Chicago, IL: Aldine.

Gold, A. H., Malhotra, A., \& Segars, A. H. (2001). Knowledge management: An organizational capabilities perspective. Journal of management information systems, 18(1), 185-214. Retrieved from https://www. researchgate.net/publication/220591588 Knowledge Management An Organizational Capabilities Perspective/link/09e4150b6486954612000000/ download

Guba, E. \& Lincoln, Y. (2005). Paradigmatic controversies, contradictions and emerging confluences. In E. Guba, and Y. Lincoln. (Eds.). The Sage Handbook of Qualitative Research (pp. 191-215). Thousand Oaks, CA: Sage.

Hazlett, S., McAdam, R., \& Beggs, V. (2008). An exploratory study of knowledge flows: A case study of Public Sector Procurement. Total Quality Management, 19(1-2). https://doi.org/10.1080/14783360701602205

Jain, A. K., \& Jeppesen, H. J. (2013). Knowledge management practices in a public sector organization: The role of leaders' cognitive styles. Journal of Knowledge Management, 17(3), 347-362. https://doi.org/10.1108/JKM-11-2012-0358

Janissek-Muniz, R., \& Blanck, M. R. M. (2014). Weak signals management, entrepreneurship and uncertainty: A relational theoretical essay under the perspective of intelligence. Anais do CONTECSI - International Conference on Information Systems and Technology Management. São Paulo, SP, Brazil, 11. https://doi. org/10.5748/9788599693100-11CONTECSI/COMM$\underline{625}$

Janissek-Muniz, R., Lesca, H., \& Freitas, H. (2006). Inteligência estratégica antecipativa e coletiva para tomada de decisão. Revista Organizaçóes em Contexto, 2(4), 92118. Retrieved from http://www.ufrgs.br/gianti/files/ artigos/2007/2007 organizacao em contexto rjm hl hf inteligencia antecipativa coletiva.pdf

Johnston, E. W., \& Hansen, D. L. (2011). Design lessons for smart governance infrastructures. In A. P. Balutis, D. Ink. Transforming American Governance: Rebooting the public square (pp. 197-212). London: Routledge.

Klering, L. R., Porsse, M. C. S., \& Guadagnin, L. A. (2010). Novos Caminhos da Administração Pública Brasileira. Análise, 21(1), 4-17. Retrieved from https:// www.researchgate.net/publication/277097960 Novos Caminhos da Administracao Publica Brasileira

Linders, D., Liao, C. Z. P., \& Wang, C. M. (2015). Proactive e-Governance: Flipping the service delivery model from pull to push in Taiwan. Government Information Quarterly, 35(Supl 4), 68-76. https://doi.org/10.1016/j.giq.2015.08.004

Lindner, F., \& Wald, A. (2011). Success factors of knowledge management in temporary organizations. International Journal of Project Management, 29(7), 877-888. https://doi.org/10.1016/j.ijproman.2010.09.003
Liu, X., \& Zheng, L. (2015). Cross-departmental collaboration in one-stop service center for smart governance in China: Factors, strategies and effectiveness. Government Information Quarterly, 35(Supl4), 54-60. https://doi.org/10.1016/j.giq.2015.12.001

McBride, K., Aavik, G., Kalvet, T., \& Krimmer, R. (2018). Cocreating an open government data driven public service: The case of Chicago's Food inspection forecasting model. https://doi.org/10.24251/HICSS.2018.309

Malomo, F., \& Sena, V. (2017). Data intelligence for local government? Assessing the benefits and barriers to use of big data in the public sector. Policy \& Internet, 9(1), 7-27. https://doi.org/10.1002/poi3.141

Mao, H., Liu, S., Zhang, J., \& Deng, Z. (2016). Information technology resource, knowledge management capability, and competitive advantage: The moderating role of resource commitment. International Journal of Information Management, 36(6), 1062-1074. https://doi.org/10.1016/j.ijinfomgt.2016.07.001

Ministério do Planejamento. (2016). Orçamento e Gestão. Programa GESPÚBLICA, Instrumento para Avaliação da Gestão Pública-250 Pontos. Brasília, DF: Secretaria de Gestão Pública, 2015. Versão 1/2016. Retrieved from http:// www.gespublica.gov.br/sites/default/files/documentos/ gagp-250 pontos novo.pdf

Monavvarian, A., \& Kasaei, M. (2007). A KM model for public administration: The case of Labour Ministry. Vine, 37(3), 348-367. https://doi.org/10.1108/03055720710825654

Myers, M. D. (2013). Qualitative research in business and management. Thousand Oaks, CA: Sage Publications.

Nonaka, I. (1994). A dynamic theory of organizational knowledge creation. Organization Sscience, 5(1), 14-37. Retrieved from www.jstor.org/stable/2635068

Nonaka, I., \& Konno, N. (1998). The concept of "Ba": Building a foundation for knowledge creation. California Management Review, 40(3), 40-54. Retrieved from http://home.business. utah.edu/actme/7410/Nonaka\%201998.pdf

Nonaka, I., \& Takeuchi, H. (2008). Teoria da criação do conhecimento organizacional. In I. Nonaka, H. Takeuchi. Gestáo do conhecimento (pp. 54-90). Porto Alegre: Bookman.

Paula, G., de, \& Rover, A. J. (2012). O governo eletrônico e a atividade de inteligência. Revista Democracia Digital e Governo Eletrônico, 1(6) 216-237. Retrieved from http:// buscalegis.ufsc.br/revistas/index.php/observatoriodoegov/ article/view/89

Paula, A. P. P., de. (2005). Administração pública brasileira entre o gerencialismo e a gestáo social. Revista de Administração de Empresas, 45(1), 36-49. http://dx.doi.org/10.1590/S0034-75902005000100005

Pee, L. G., \& Kankanhalli, A. (2016). Interactions among factors influencing knowledge management in public-sector organizations: A resource-based view. Government Information Quarterly, 33(1), 188-199. https://doi.org/10.1016/j.giq.2015.06.002 
Pereira, L.C.B. (1996). Da administração pública burocrática à gerencial. Revista do Serviço Público, 47(1), 1-28. https://doi.org/10.21874/rsp.v47i1.702

Przeybilovicz, E., Cunha, M.A., Macaya, J. F. M., \& Albuquerque, J. P. D. (2018 January). A Tale of two "Smart Cities": Investigating the echoes of new public management and governance discourses in Smart City Projects in Brazil. Proceedings of the Hawaii International Conference on System Sciences, Honolulu, HI, USA, 51.

Ragin, C. C. (2000). Fuzzy-set social science. Chicago: University of Chicago Press.

Ragin, C. C. (2005). From fuzzy sets to crisp truth tables. Retrieved from http://compasss.org/wpseries/Ragin2004.pdf

Ragin, C. C. (2008). Redesigning social inquiry: Fuzzy sets and beyond. Chicago: University of Chicago Press. https://doi.org/10.7208/chicago/9780226702797.001.0001

Rezende, D. A., \& Frey, K. (2005). Administração estratégica e governança eletrônica na gestão urbana. Revista Eletrônica de Gestão de Negócios, 1(1), 51-59. Retrieved from https:// www.unisantos.br/mestrado/gestao/egesta/artigos/24.pdf

Rezende, D. A. (2012). Projeto de Organizational Business Intelligence (OBI): modelo organizacional de três organizaçóes paranaenses. Anais do CONTECSI Congresso Internacional de Gestão da Tecnologia e Sistemas de Informação, Sáo Paulo, SP, Brazil, 9.

Ribeiro, L. M. D. P., Pereira, J. R., \& Benedicto, G. C. D. (2013). As reformas da administração pública brasileira: Uma contextualização do seu cenário, dos entraves e das novas perspectivas. Anais EnANPAD, Rio de Janeiro, RJ, Brazil, 37.

Riege, A., \& Lindsay, N. (2006). Knowledge management in the public sector: stakeholder partnerships in the public policy development. Journal of knowledge management, 10(3), 24-39. https://doi.org/10.1108/13673270610670830

Rihoux, B. \& Ragin, C. C. (2009). Configurational comparative methods. Qualitative Comparative Analysis (QCA) andrelated techniques. https://dx.doi.org/10.4135/9781452226569

Rios, F. D. C., Strauss, L. M., Janissek-Muniz, R., \& Brodbeck, A. G. (2011). Inteligência competitiva, empresarial, estratégica ou de negócios? Um olhar a partir da Administração de Empresas. Facef Pesquisa, 14(2), 225238. Retrieved from http://periodicos.unifacef.com.br/ index.php/facefpesquisa/article/view/278/269

Schedler, K., Guenduez, A.A., \& Frischknecht, R. (2019). How smart can government be? Exploring barriers to the adoption of smart government. Information Polity, 24(1), 3-20. https://doi.org/10.3233/IP-180095
Scholl, H. J., \& Scholl, M. C. (2014). Smart governance: A roadmap for research and practice. iConference 2014 Proceedings, Illinois, CH, USA. https://doi.org/10.9776/14060

Schutte, N., \& Barkhuizen, N. (2015). Knowledge management and sharing in local government: A social identity theory perspective. Electronic Journal of Knowledge Management, 13(2), 131-142. Retrieved from http://www.ejkm.com/volume13/issue2

Secchi,L.(2009).Modelosorganizacionaisereformasdaadministração pública. Revista de Administração Pública, 43(2), 347-369. https://doi.org/10.1590/S0034-76122009000200004

Shinoda, A. C. M., Maximiano, A. C. A., \& Sbragia, R. (2015). Gestão do conhecimento em organizaçóes orientadas para projetos. Gestão e Projetos: GeP, 6(1), 95-110. http://doi.org/10.5585/gep.v6i1.111

Terra, J. C. C., \& Almeida, C. (2008). Gestão do Conhecimento e Inteligência Competitiva: duas faces da mesma moeda. Terra Fórum Associados. Retrieved from http:// docplayer.com.br/84936701-Gestao-do-conhecimentoe-inteligencia-competitiva-duas-faces-da-mesma-moeda. $\underline{\mathrm{html}}$

Tzortzaki, A. M., \& Mihiotis, A. (2014). A review of knowledge management theory and future directions. Knowledge and Process Management, 21(1), 29-41. https://doi.org/10.1002/kpm.1429

Valle-Cruz, D., \& Sandoval-Almazan, R. (2018, May). Towards an understanding of artificial intelligence in government. Proceedings of the Annual International Conference on Digital Government Research: Governance in the Data Age, Delft, Netherlands, 19. https://doi.org/10.1145/3209281.3209397

Voronchuk, I., \& Starineca, O. (2014). Knowledge management and possibilities of professional development in public sector. European Integration Studies, (8), 168-179. https://doi.org/10.5755/j01.eis.0.8.6844

Weber, R. P. (1990). Quantitative applications in the social sciences: basic content analysis, $2^{\text {nd }}$ ed. Thousand Oaks: Sage.

Welsh, W (2014, June 5). Smart Government: All about disruption. Information Week. https://www.informationweek.com/ government/open-government/smart-government-allabout-disruption/d/d-id/1269459

Wiig, K.M.(1997). Knowledgemanagement: Wheredid itcomefrom and where will it go? Expert Systems With Applications, 13(1), 1-14. https://doi.org/10.1016/S0957-4174(97)00018-3

Wiig, K. M. (2002). Knowledge management in public administration. Journal of Knowledge Management, 6(3), 224-239. https://doi.org/10.1108/13673270210434331 


\section{Autoria}

\section{Claudia Melati*}

Universidade Federal do Rio Grande do Sul, Escola de Administração

Rua Washington Luiz, no 855, Centro Histórico, 90010-460, Porto Alegre, RS, Brasil.

E-mail: cmelati@yahoo.com.br

(D) https://orcid.org/0000-0002-9369-0113

\section{Raquel Janissek-Muniz}

Universidade Federal do Rio Grande do Sul, Escola de Administração

Rua Washington Luiz, no 855, Centro Histórico, 90010-460, Porto Alegre, RS, Brasil.

E-mail: rjmuniz@ufrgs.br

(1) https://orcid.org/0000-0002-0657-6559

\section{Carla Maria Marques Curado}

Universidade de Lisboa, Instituto Superior de Economia e Gestão.

Rua do Quelhas, no 6, 1200-781, Lisboa, Portugal.

E-mail: ccurado@iseg.ulisboa.pt

(1) https://orcid.org/0000-0002-2608-8982

* Autora Correspondente

\section{Financiamento}

Os autores afirmam que não houve apoio financeiro.

\section{Conflito de Interesses}

Os autores informaram que não há conflito de interesses.

\section{Direitos Autorais}

A RAC detém os direitos autorais deste conteúdo.

\section{Verificação de Plágio}

A RAC mantém a prática de submeter todos os documentos aprovados para publicaçáo à verificaçáo de plágio, mediante o emprego de ferramentas específicas, e.g.: iThenticate.

\section{Contribuições dos Autores}

$1^{\text {a }}$ autora: conceitualização (igual); curadoria de dados (líder); análise formal (igual); investigação (líder); metodologia (igual); administração do projeto (igual); supervisão (igual); visualização (igual); redação - rascunho original (líder); redação - revisão e edição (igual).

$2^{a}$ autora: conceitualização (igual); curadoria de dados (apoio); análise formal (igual); investigaçáo (apoio); metodologia (igual); administração do projeto (igual); supervisão (igual); visualização (igual); redação - rascunho original (apoio); redação - revisão e edição (igual).

$3^{a}$ autora: conceitualização (igual); curadoria de dados (apoio); análise formal (igual); investigaçáo (apoio); metodologia (igual); administração do projeto (igual); supervisão (igual); visualização (igual); redação - rascunho original (apoio); redação - revisão e edição (igual).

\section{Método de Revisão por Pares}

Este conteúdo foi avaliado utilizando o processo de revisão por pares duplo-cego (double-blind peer-review). A divulgação das informaçóes dos pareceristas constantes na primeira página e do Relatório de Revisão por Pares (Peer Review Report) é feita somente após a conclusão do processo avaliativo, e com o consentimento voluntário dos respectivos pareceristas e autores.

\section{Disponibilidade dos Dados}

Todos os dados e materiais foram disponibilizados publicamente por meio da plataforma Mendeley e podem ser acessados em:

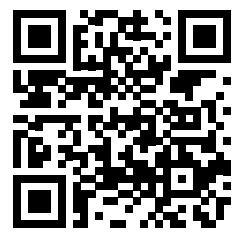

Melati, Claudia; Janissek-Muniz, Raquel; Curado, Carla (2020), "Data for: "Decisionmaking quality of public managers: contributions from Intelligence and Knowledge Management" published by RAC - Revista de Administração Contemporânea”, Mendeley Data, v3. http://dx.doi.org/10.17632/j4jgpmnp7m.3 